\title{
Utveckling av en evidensbaserad och objektiv familjehemsutredning
}

\author{
Huvudsökande: Rebecca Willén (IGDORE)
}

Medverkande: Ola Kronkvist (Linnéuniversitetet)

Kontaktperson rörande denna forskningsansökan är Rebecca Willén, e-post: rebecca.willen@igdore.org.

\section{Sammanfattning (svenska)}

Behovet av familjehem i Sverige är stort och de hem som finns räcker inte till alla som behöver det. Många unga placeras därför istället på institution, trots att det rådande evidensläget antyder att långtidsutsikterna efter institutionsvård är sämre än om ungdomen istället placerats i familjehem. Presumtiva familjehem genomgår en utredning där deras lämplighet bedöms. Den vanligaste svenska metoden för detta är Nya Kälvesten (Willén \& Kronkvist, 2021). Metoden granskades vetenskapligt för första gången av Willén och Kronkvist som fann den oetisk med hög risk för subjektivitet. Samtidigt kan en underanvändning noteras av de evidensbaserade metoderna Familjehemsvinjetter och BRA-fam. Internationell forskning har även visat på en underutnyttjad potential rörande tillämpning av psykologiska mätinstrument i familjehemsutredningar. Det aktuella projektet avser utveckla och testa en strukturerad utredningsmodell bestående av flertalet enskilda metoder (t. ex. BRA-fam och Familjehemsvinjetter) som var och en stöds av vetenskaplig forskning. Studie 1 undersöker och testar användningspotentialen i psykologiska bedömningsinstrument (t. ex. personlighetstester). Studie 2 utvecklar och testar en strukturerad helhetsmodell för familjehemsutredningar baserad bland annat på resultaten från Studie 1, men som också tar avstamp i rättspsykologisk forskning och erfarenheter från andra utredande samhällskontexter (t. ex. asyl- försäkrings- och brottsutredningar). Till modellen kommer även en handbok och projekthemsida utvecklas. Studie 2 förbereder även för långtidsuppföljning av antal sammanbrott i godkända familjer. Alla projektets studier etikprövas och preregistreras före datainsamling. Anonymiserade dataset kommer att göras fritt tillgängliga, liksom projektets forsknings- och utbildningsmaterial.

\section{Sammanfattning (engelska)}

There is a great need for foster carers in Sweden and the number of existing foster homes is not enough for everyone who needs it. Many young people are therefore placed in institutions instead despite current evidence suggesting that the long-term prospects for institutional care are worse than placement in foster homes. Prospective foster homes undergo an investigation where their suitability is assessed. The most common Swedish method is the New Kälvesten method (Willén \& Kronkvist, 2021). The method was scientifically reviewed for the first time by Willén and Kronkvist 
who found it unethical with a high risk of subjectivity. At the same time, an underuse can be noted of the evidence-based Swedish methods Familjehemsvinjetter and BRA-fam. International research has also shown an underutilized potential regarding the application of psychological measurements in assessments of prospective foster homes. The current project intends to develop and test an investigation model consisting of several individual methods (e.g. BRA-fam and Familjehemsvinjetter), each of which is supported by scientific research. Study 1 examines and tests the potential for application of psychological instruments (e. g. personality tests). Study 2 develops and tests a structured assessment model based on the results from Study 1 and implementing knowledge derived from the scientific field of investigative psychology and investigative practical contexts (e.g. asylum, insurance and criminal investigations). A handbook and project website will be developed as part of the investigative model. Study 2 also prepares for long-term follow-up of approved families. Both studies will be ethically reviewed and preregistered before data collection. Anonymised datasets will be made freely available as well as the project's research and training materials.

\section{Syfte, frågeställningar, teorianknytning, bakgrund och projektets originalitet}

Ungefär 20.000 barn i Sverige bor i familjehem (Socialstyrelsen, 2020a), och ännu fler hade behövt det men kan på grund av bristen på familjehem inte få det (IVO, 2017). Många placeras därför istället på institution trots att forskning tyder på att specialiserade familjehem ger bättre resultat än institutionsvård (SBU, 2018). De institutionsplacerade barnen är överrepresenterade bland de som senare blir inneliggande patienter vid psykiatriska vårdavdelningar eller döms för brott, och de skaffar sig mer sällan utbildning utöver grundskola eller etablerar sig på arbetsmarknaden (Vinnerljung \& Sallnäs, 2008; Sacker, Lacey, Maughan, \& Murray, 2021). Nya rekommendationer från Socialstyrelsen (2021b) slår därför fast att fler ungdomar måste få plats i (specialiserade) familjehem istället för att placeras på institution. Detta innebär att rekryteringen av nya familjehem behöver öka ytterligare. I en ny studie fann dock Willén och Kronkvist (2021) att denna målsättning inte är förenlig med målsättningen hos den idag vanligaste metoden för att utreda presumtiva familjehem: att endast ett fåtal sökande ska godkännas.

Det aktuella projektet bygger vidare på ett pågående arbete av Willén och Kronkvist (2021; manus under produktion) där Nya Kälvestenmetoden granskats ur ett rättspsykologiskt perspektiv. Studien visade på allvarliga brister i metodens etik och tillförlitlighet, brister som delas med

föregångsmetoden Kälvesten. Tillsammans utgör dessa metoder någonstans mellan 82 (SBU, 2017) och 90 procent (Willén \& Kronkvist) av familjehemsutredningarna i Sverige.

\section{Rättspsykologiska perspektiv på utredande intervjuer}

Utredande intervjuer förekommer i flertalet samhällskontexter. Polis- tull- och domstolsväsende intervjuar målsägare, vittnen, och misstänkta/tilltalade. Migrationshandläggare intervjuar asylsökanden för att utreda de skäl som läggs fram som stöd till ansökan. Socialtjänsten intervjuar vårdnadshavare, barn, och presumtiva familjehem och adoptionsföräldrar i syfte att säkerställa att barnet får sina lagstadgade omsorgsbehov och rättigheter tillfredsställda. Oavsett inom vilken 
kontext en utredande intervju genomförs är det övergripande syftet alltid detsamma: att på ett rättssäkert sätt få fram relevant, fullständig och tillförlitlig information som kan leda utredaren till ett så objektivt sett korrekt beslut som möjligt (Kronkvist, 2020).

Utredande intervjuer (investigative interviewing) är ett praktiknära rättspsykologiskt forskningsfält som bland annat utvecklar och utvärderar nya och gamla intervju- och analysmetoder. Uppslag till ny forskning kommer ofta från praktiker själva som i sitt arbete identifierat behov av evidensbaserad vägledning. Två av de intervjutekniker (SUE och Scharff) som idag hör till rekommenderad praxis av amerikanska Federal Buraeu of Investigation / High-Value Detainee Interrogation Group (2016) tillämpades från början av utredare själva utan evidensbas men har därefter beforskats och vidareutvecklats (bl. a. av de två forskare som ligger bakom aktuell ansökan). Fältet har även studerat hur frågor bör formuleras för att vara lättbegripliga och inte väcka fel associationer som ger spekulationer eller minnesfel (t. ex. Loftus \& Palmer, 1974). Andra välstuderade frågor är hur barn och vuxna minns och berättar om vardagliga (t. ex. Johnson, Foley, Suengas, \& Raye, 1988) såväl som mer ovanliga eller traumatiska händelser de varit med om (t. ex. Orbach, Lamb, Sternberg, Williams, \& Dawud-Noursi, 2001), och hur berättelserna och minnet påverkas av att personen redan berättat många gånger om det som hänt (t. ex. Suengas \& Johnson, 1988). Här finns också forskning om till exempel hur man kan underlätta för fåordiga intervjupersoner att berätta mer (Scoboria, Memon, Trang, \& Frey, 2013), och svårigheterna med att specificera händelser man varit med om många gånger (Means, Nigam, Zarrow, Loftus, \& Donaldson, 1989; Roberts \& Powell, 2001; Willén, Granhag, \& Strömwall, 2016). Det finns också omfattande utvärderingar av utredande intervjutekniker (t. ex. La Rooy et al., 2015; Memon, Meissner, \& Fraser, 2010).

Under 1980- och 90-talen uppstod en infekterad debatt om hur och vad man minns av traumatiska händelser och huruvida vissa intervjutekniker kunde orsaka falska minnen, till exempel av så kallade bortträngda minnen. Minnesforskare lade mer vikt vid studier som baserats på experiment (som inte gav stöd för fenomenets existens) medan kliniska psykologer och psykoterapeuter ville lyssna mer på fallstudier och klinisk erfarenhet (där fenomenet beskrivits; McNally, 2005). En svensk kvarleva av epoken då psykologer och psykoterapeuter trodde att bortträngda minnen fanns, i kombination med en psykodynamisk inriktning på de utredande intervjuerna, är de idag avskrivna domarna mot Sture Bergwall / Thomas Quick. 90-talets debatt, och otaliga frikännanden i bland annat USA av framförallt män som hade dömts oskyldiga, ledde till krav på evidens och en upprätning av de utredande intervjumetoder som användes i brottsutredningar. Under 2000- och 10talen har upprätningen nått asylutredningar (UNHCR, 2013). Inom det sociala fältet tillämpas dock ännu något av en psykodynamisk inriktning, med en stark tro på att utredaren/analytikern har en unik blick som kan avgöra intervjupersonens sanna natur.

\section{Familjehemsutredningar i Sverige}

Svenska familjehemsutredningar ska enligt Socialstyrelsens föreskrifter (SOSFS 2012:11) omfatta intervjuer, hembesök, och referenstagning (kap. 4, 4 §). Registeruppgifter ska även inhämtas från socialnämnden, och Socialstyrelsen rekommenderar inhämtning av uppgifter även från Kronofogdemyndigheten och Försäkringskassan (5 §). Om den tilltänkta familjen redan varit familjehem ska också referenstagning ske från de kommuner som haft placeringar hos familjen (7 
$\S$ ). Vidare ska utredningen i sin helhet samla in uppgifter om (kap. 4, 3 §) 1. familjens sammansättning, bakgrund, livssituation och levnadsvanor, 2. boende och närmiljö, 3. varje tilltänkt familjehemsförälders personliga förutsättningar, egenskaper och omsorgsförmåga samt 4. varje tilltänkt familjehemsförälders inställning till uppdraget.

I Sverige används främst tre metoder för att utreda lämpligheten hos familjehem (SBU, 2017): Bedömning vid rekrytering av familjehem (BRA-fam), Kälvestenmetoden (inkl. modifierade versioner), och Nya Kälvestenmetoden. Utöver detta förekommer ytterligare några metoder, så som Familjehemsvinjetter (Willén \& Kronkvist, 2021), Intervju om anknytningsstil (IAS) och PRIDE (SBU, 2017). Nedan följer en kort genomgång av de tre vanligaste metoderna och av metoden Familjehemsvinjetter som är av särskilt intresse för det aktuella projektet. Störst vikt i genomgången läggs vid Nya Kälvestenmetoden som förut aldrig beskrivits.

\section{BRA-fam}

BRA-fam är ett standardiserat och evidensbaserat frågeformulär utvecklat av Socialstyrelsen (2014). Formuläret används som en screeningmetod för att utgöra en första grov sållning bland de sökande. Instrumentet informerar genom sina 59 frågor sökande familjer om vad som krävs och förväntas av ett familjehem och instrumentet är på så vis tänkt att framförallt resultera i en självsållning. Frågorna och hur svaren på frågorna ska tolkas har grund i vetenskaplig forskning och denna grund beskrivs noggrant i den tillhörande manualen. Vid SBU:s genomgång 2017 fann man att BRA-fam användes i relativt stor utsträckning (ca 30-50\%) av familjehemsutredarna. Med tanke på att BRA-fam är den enda standardiserade och evidensbaserade metod som används i Sverige, utöver Familjehemsvinjetter, kan dock siffrorna anses låga. BRA-fam med manual finns enkelt tillgängligt utan kostnad på Socialstyrelsens hemsida. Familjehemsutredare behöver ingen utbildning i metoden för att använda den.

\section{Kälvestenmetoden}

Kälvestenmetoden utvecklades på 1960- och 70-talen av psykologen och forskaren Anna-Lisa Kälvesten med kollegor (Jonsson \& Kälvesten, 1964; Kälvesten \& Meldahl, 1972). Intervjumetoden har en psykodynamisk grund och innefattar cirka 150-190 frågor, plus eventuella följdfrågor, som beräknas kunna besvaras inom ungefär 4-5 timmar. Möjlighet att dela upp intervjun på flera tillfällen finns. Två utredare ska alltid närvara under intervjun.

Intervjun spelas inte in, utan istället ska intervjuaren skriva ned intervjupersonens svar ordagrant. Intervjusvaren ska sedan analyseras av en person som tränats i att analysera metoden. Analysen innebär en helhetsbedömning som tar hänsyn till familjens funktionsnivå, uppfostringstyp, och makerelationen i familjen (Rasmusson \& Regnér, 2013). När det är dags för analys träffas analytikern och de två utredarna som närvarat under intervjun. För analytikern läser de två utredarna upp intervjusvaren ordagrant i form av ett slags rollspel.

”Det faktum att intervjuarna läser sina frågor och personens ordagranna svar ur formulären gör att delar av intervjun presenteras så gott som i sin grundform [...] [Detta leder till en] upplevelse av att höra intervjupersonerna tala själva. Metoden tedde sig då [...] kraftfull och gav möjlighet att skilja mellan intervjupersonernas egna svar och 
intervjuarnas eventuella tolkningar av desamma. Men dessutom blev det en särskild dramaturgi.” (s. 299, Rasmusson \& Regnér, 2013)

Analysen av Kälvestenmetodens efterföljare, Nya Kälvestenmetoden, går till på samma sätt och processens tillförlitlighet har kritiserats kraftigt av Willén \& Kronkvist (2021). Att ordagrant skriva ned vad som sägs i en intervju, så kallad transkribering, brukar ta ungefär 6-7 gånger realtiden. En intervju som pågår under fyra timmar tar således minst 24 timmar, effektiv arbetstid, att skriva ned ordagrant. Den analys som görs av intervjun, och som således ligger till grund för bedömningen av det presumtiva familjehemmet, baseras helt och hållet på den individuella utredarens förmåga att lyssna och samtidigt i realtid lyckas skriva ned det mest relevanta av det som sägs. Vidare baseras analysen på utredarnas förmåga att objektivt återge alla relevanta delar av intervjun i sin helhet för analytikern.

Vidare kan det kritiseras att analysprocessen ger stort utrymme för kategoriska och intuitiva slutsatser (kategorisk intuitiv deduktion; Moritz, 1981). Thiblin och Michard (2015; s. 74) beskriver denna typ av feltänk hos rättsläkare på följande sätt:

"en tendens att göra kategoriska tolkningar av ospecifika fynd [...] utan hänsyn till den fundamentala vetenskapliga principen att en sådan kategorisk deduktion endast kan göras om det på ett övertygande sätt har visats att denna typ av fynd inte finns i kontrollfall. [... R]ättsläkare som arbetar på detta sätt är behäftade med en oförmåga att minnas att de har sett liknande skador som har uppkommit på annat sätt än det som hävdas.”

Författarna fortsätter (s. 74):

”[L]äkare som gör kategoriska intuitiva bedömningar är populära [...] hos polis och åklagare för att experten framstår som empatisk och kunnig.”

På samma sätt kan man tänka sig att Kälvestens- och Nya Kälvestensanalytiker funnit uppskattning bland socialarbetare då de med säkerhet delar med sig av vad de kommit fram till i sina tolkningar av intervjupersonens lämplighet att bli familjehem.

Kälvestenmetoden finns beskriven på ett övergripande sätt i en bok av Rasmusson och Regnér (2013). Ursprungliga versioner av frågeformuläret finns tillgängliga i tryckta böcker av till exempel Kälvesten och Meldahl, men böckerna är svårtillgängliga och versionerna inaktuella. Manual ska finnas enligt Rasmusson och Regnér. Det finns flertalet utbildningar i metoden. Kostnaden för att genomgå en av de mest välkända utbildningarna är för närvarande 19.600 kr per person (exklusive moms).

\section{Nya Kälvestenmetoden}

Nya Kälvestenmetoden (NK) togs fram 2011 av en psykolog med psykoterapeutexamen och en socionom som båda tidigare utrett familjehem med den ursprungliga Kälvestenmetoden. Medan den ursprungliga Kälvestenmetoden länge dominerat sektorn (SBU, 2017) tyder den senaste genomgången på att NK idag har en något större utbredning än den ursprungliga metoden (Willén \& Kronkvist, 2021). 
NK inleds med en första screening med BRA-fam. Efter hembesök, registerutdrag, och flertalet samtal med den sökande familjen hålls NK-intervjun som består av antingen 127 eller 142 frågor. Willén och Kronkvist har fått tillgång till i stort sett fullständigt material och intervjun har därmed för första gången kunnat analyseras vetenskapligt.

NK-intervjun får pågå i max tre timmar inklusive en tio minuters paus. Under intervjun ska utredaren ordagrant skriva ned allt intervjupersonen säger, även sådant som kan verka trivialt eller irrelevant. Intervjun får inte spelas in. Även icke-verbala beteenden ska noteras, till exempel om intervjupersonen skrattar. Syftet är inte att samla in fakta utan att genom språkanalys bedöma huruvida den sökande har tillräckligt med det som i metoden kallas "känslomässig tillgänglighet och reflekterande sinnelag”. Detta mäts genom att en extern analytiker lyssnar när utredarna läser upp intervjupersonens svar (se Kälvestensmetoden). Det uppmuntras att utredaren använder samma tonläge och pauser som intervjupersonen gjorde. När utredaren läst upp alla intervjusvar delar analytikern på plats med sig av den bedömning hen gjort under tiden uppläsningen pågått.

Bedömningen baseras på 6 kriterier (kvalitet, kvantitet, relevans, begriplighet, affekter, mentalisering) som alla mäts binärt (uppfyllt kriterium: ja/nej) av analytikern. Kvalitet avser sanning, kvantitet avser att intervjupersonen ska prata lagom mycket (varken för lite eller för mycket), relevans innebär att hen håller sig till det som är relevant, och begriplighet att personen talar klart och tydligt. Affekter avser medvetenhet om sina egna och andras känslor och förmågan att härbärgera dessa känslor, och mentalisering förmågan att tänka och känna om sig själv och andra. Denna analys resulterar i en binär helhetsbedömning: Har den sökande tillräckligt med känslomässig tillgänglighet och reflekterande sinnelag?

Paus under intervjun får inte tas av hänsyn till intervjupersonen utan den är till för utredaren och det är hen ensam som beslutar om och när den ska äga rum. Syftet är att utsätta intervjupersonen för sådan stress att hen inte klarar av att hålla upp en fasad. Detta uttalade syfte understryks genom att utredaren instrueras att inte titta på eller interagera med intervjupersonen. Man anser att en sökande som tolererar denna typ av stress är bättre lämpad att bli familjehem än någon som inte kan eller vill utsättas för sådan stress. Frågorna handlar om intervjupersonens barndom, föräldrarnas och syskonens relationer, relationen till eventuella egna barn, och om sexualitet. Flera frågor har inspirerats av Adult Attachment Interview (AAI) som syftar till att i forskningssammanhang mäta anknytningsstil, och en fråga är hämtad från ett annat test (Hazan \& Shaver, 1987) av anknytningsstil som används i forskningssammanhang. Många forskare som specialiserat sig inom anknytningspsykologi avråder från användning av mätningar av anknytningsstil i sociala utredningar (Forslund et al., 2021). Det framhålls särskilt att det inte går att använda enstaka frågor från AAI för att mäta anknytningsstil och att försök till mätningar baserade på intervjuer som inte spelats in och transkriberats, liksom intervjuer som gjorts under tidspress och utan inkännande närvaro från intervjuaren, utgör omfattande risk för att bli felaktiga (Willén \& Kronkvist, 2021).

Grundarna menar att NK har vetenskaplig grund eftersom den utgår från tre evidensbaserade intervjumetoder (AAI, mentaliserings-, och affektintervjun). Willén \& Kronkvists analys har dock visat att procedurerna för genomförandet av intervjun och analysen är såpass väsensskilda från de evidensbaserade metoderna att hänvisningen till dem blir bedräglig då det ger ett falskt intryck av evidens. Vidare hävdas felaktigt i ett undervisningshäfte att metoden är standardiserad. 
BRA-fam-manualen säger att riskfaktorer ska vägas mot skyddsfaktorer, något som NK tar starkt avstånd från. NK är designad för att underskatta lämplighet. Detta innebär med nödvändighet att sökande familjer som egentligen är lämpliga felaktigt bedöms som olämpliga, och att antalet godkända familjehem blir lägre än vad det hade kunnat vara. Detta innebär sannolikt i sin tur att fler unga än nödvändigt placeras på institution istället för i familjehem. Användning av BRA-fam ingår i NK men det ges ingen vägledning om hur de två kontrasterande perspektiven ska förenas.

NK beskrivs på ett övergripande sätt i ett tryckt häfte som kan beställas av en av metodens grundare. Frågeformuläret finns inte tillgängligt för andra än de som gått utbildning i metoden. Metoden saknar manual (Willén \& Kronkvist, 2021). Utredare som utbildats i metoden instrueras att inte spara frågeformuläret på kommunens eller bolagets datorer eller nätverk eftersom utredare som saknar utbildning då kan komma åt materialet. Två utbildningar finns i metoden. Behörig är den som i sitt arbete utreder familjehem. Kostnaden för utbildningen är 14.000-15.000 kr per person (exkl. moms). För att analysera intervjun krävs kunskaper i affekt- anknytnings- och mentaliseringsteori, samt socionom- eller psykologexamen med påbyggnadsutbildning så som psykoterapiutbildning och/eller handledarutbildning. Utöver detta krävs gedigen yrkeserfarenhet. Kostnaden för analyskursen framgår för närvarande inte på någon av de två hemsidorna. En vanlig kostnad för att få en intervju analyserad är 5000 kr exklusive moms.

\section{Familjehemsvinjetter}

Familjehemsvinjetter är en vinjettbaserad intervjumetod baserad på Casey Home Assessment Protocol - Fostering Challenges (CHAP-FC ) som har anpassts till svenska förhållanden av Socialstyrelsen (2020). Den amerikanska versionen ingår som ett instrument av flera i helhetsmetoden Casey Foster Family Assessment (CFFA) som utvecklats av amerikanska forskare.

Willén och Kronkvist (2021) fann 8 privata familjehemskonsulenter som på sina hemsidor rapporterade användning av Familjehemsvinjetter. Detta kan jämföras med 57 som använde Nya Kälvesten, och 47 som sade sig använda någon form av Kälvesten (det finns skäl att tro att några av dessa egentligen är Nya Kälvesten; totala antalet privata aktörer som angav metod på sin hemsida var 113). Familjehemsvinjetter lanserades i Sverige först 2020 och man kan således anta att användningen kommer öka de närmaste åren.

Familjehemsvinjetter med manual finns enkelt tillgängligt utan kostnad på Socialstyrelsens hemsida. Familjehemsutredare behöver ingen utbildning i metoden för att använda den.

\section{Föreliggande projekt}

Kälvestenmetoden har kritiserats av forskare i minst 20 år och Willén och Kronkvist (2021) framför hård kritik mot NK och Kälvesten för bristande etik och hög risk för subjektivitet. Behovet av fungerande utredningsmetoder framgår nu senast i en DN-artikel (2021) om ett barn som ska ha utsatts för missförhållanden i de familjehem hon var placerad i. Placerande kommun använder Kälvesten för att utreda vilka som ska få bli familjehem. Även om en viss andel olämpliga familjehem alltid kommer att missas, oavsett vilken utredningsmetod som används, så finns det ett 
uppenbart utrymme för förbättringar i utredningsprocessen av presumtiva familjehem. Framförallt behövs etiska metoder med stark evidens, och metoderna behöver vara standardiserade och öppet tillgängliga, åtminstone för forskare, för att möjliggöra utvärderingar. BRA-fam och Familjehemsvinjetter är i nuläget de enda svenska metoder som uppfyller dessa kriterier. Det aktuella projektet avser bygga vidare på dessa genom att (1) komplettera dem med ytterligare evidensbaserade instrument, och (2) utveckla och testa en ny utredningsmodell som inkluderar nämnda metoder.

\section{Studiedesign, metoder för datainsamling och analys}

Det aktuella projektets mål är att utveckla och testa en ny helhetsmodell för utredning av familjehem i Sverige. Modellen kommer att bestå av flertalet enskilda metoder som i sig har god evidensgrund, så som BRA-fam och Familjehemsvinjetter. Utöver detta kommer modellen innefatta (rätts)psykologisk och i viss mån polisiär utredningskunskap där grundläggande utbildning i psykologiskt beslutsfattande (t. ex. kognitiva felkällor [biases], konfidensbedömningar, intuitivt beslutsfattande) ingår. Exempel på andra utredningssammanhang där utbildning i psykologiskt beslutsfattande ingår är Gyulai, Kagan, Herlihy, Turner, Hárdi, \& Udvarhelyis (2013) handbok för migrationshandläggare.

En projekthemsida kommer att skapas där alla metoder som ingår i modellen, fullständiga manualer och utbildningsmaterial inkluderat, kommer att finnas fritt tillgängligt på samma sätt som BRA-fam och Familjehemsvinjetter idag finns öppet tillgängligt via Socialstyrelsens hemsida. Öppna licenser kommer användas i största möjliga mån för att uppmuntra och möjliggöra revideringar. Projekthemsidan kommer även innefatta de vetenskapliga artiklar som sprungit ur projektet (green eller gold open access) liksom länkar till den anonymiserade data (open data) projektets studier baserats på.

Alla projektets studier etikprövas och preregistreras före datainsamling. Anonymiserade dataset kommer att göras öppet tillgängliga, liksom projektets forsknings- och utbildningsmaterial. Projektet beräknas resultera i två vetenskapliga artiklar som alla kommer att publiceras på engelska i internationella tidskrifter.

\section{Studie 1: Identifiering och testning av lämpliga psykologiska bedömningsinstrument}

Kennedy och Thorpe (2006) föreslog att välbeprövade personlighetstester så som Hogan Personality Inventory (HPI), som används inom arbets- och organisationspsykologi för att utreda personlig lämplighet hos arbetssökande, skulle kunna användas för att bedöma lämplighet hos presumtiva familjehem. HPI är baserad på etablerad personlighetsteori (Big Five; McCrae \& Costa, 1987) och det finns idag standardiserade normeringsvärden för hundratals yrken att jämföra med. Kennedy och Thorpe jämförde värden från profilerna "Caregiving” och "Managing others” med värden från ett pilotstickprov på 17 familjehemsföräldrar. Resultaten visade på relevanta likheter och författarna drog slutsatsen att personlighetstester för arbetssökande kan ha en god användningspotential för familjehemsutredningar. Kennedy och Thorpe rekommenderar dock att 
fortsatt forskning på området undersöker potentialen även hos andra personlighetstest eftersom HPI är ett kommersiellt och mycket dyrt instrument att använda.

Andra har föreslagit mindre beprövade, men ändå potentiellt lovande instrument så som Family Hardiness Index (FHI; Hendrix \& Ford, 2003), som avser mäta tålighet. I Nya Kälvestenintervjun önskar man mäta mentaliseringsförmåga då man menar att detta är av avsevärd betydelse för familjehemsföräldrar. Ett evidensbaserat alternativ till mätning av mentalisering är The Reflective Functioning Questionnaire (RFQ; Fonagy et al, 2016) (som dessutom redan finns översatt till flertalet språk, däribland svenska, och är fritt tillgängligt på forskargruppens hemsida).

I sin översikt av bedömningsmetoder för rekrytering av familjehem beskriver Enell, Hultman, och Jergeby (2008) flertalet ytterligare vetenskapligt baserade bedömningsmetoder, varav en kom att anpassas till svenska förhållanden av Socialstyrelsen (2020; Familjehemsvinjetter). En liknande översikt har publicerats av Luke och Sebba (2013). Studie 1 bygger vidare på detta arbete genom att systematiskt gå igenom potentialen i standardiserade psykologiska bedömningsinstrument, så som personlighetsskalor och andra psykologiska tester, för att identifiera och utvärdera instrument med potential för familjehemsutredningar.

I Studie 1 går vi systematiskt igenom litteraturen (inkl. opublicerad [grå] litteratur, för att minska risken för publiceringsbias) för att identifiera psykologiska bedömningsinstrument som (1) redan används inom familjehemsutredningar, eller (2) har testats för användning inom familjehemsutredningar. Preliminärt förväntar vi oss finna två huvudkategorier av sådana instrument:

- $\quad$ Etablerade personlighetsskalor (t. ex. HPI)

- Tester av enskilda egenskaper eller färdigheter (t. ex. FHI, RFQ)

- Tester av anknytningsstil (t. ex. AAI, IAS)

Instrumentens reliabilitet, validitet, generaliserbarhet till olika populationer, och grad av relevans för bedömning av presumtiva familjehem kommer att bedömas. Arbetet kommer även beakta faktorer så som huruvida instrumenten finns fritt tillgängliga och i vilken utsträckning familjehemsutredare själva skulle kunna använda instrumenten utan extern hjälp.

Utifrån denna genomgång avser vi i samverkan med våra samarbetspartners (via programmet Connected Children, se separat intyg från forskningsledare) identifiera ett eller flera lovande instrument med god evidensbas, som kan komplettera BRA-fam och Familjehemsvinjetter inom ramen för Studie 2. Flertalet instrument kan komma att väljas ut i det fall de anses kunna komplettera varandra (dvs mäter olika saker), till exempel en personlighetsskala och ett eller flera tester av enskilda egenskaper. Om det eller de utvalda instrumenten inte redan finns översatt(a) till svenska så kommer sådan översättning ske.

Testning av det eller de utvalda instrumenten genomförs med deltagare som rekryterats via våra samarbetspartners. Deltagarna ska alla ha godkänts som familjehem. Beräkning av stickprovsstorlek kommer att ske genom statistisk poweranalys. Antalet deltagare ska vara tillräckligt högt för att kunna identifiera även små effekter med minst 80\% sannolikhet, i enlighet med nyare mer strikta 
rekommendationer rörande stickprovsstorlek inom livs- och samhällsvetenskaperna (se t. ex. Button et al., 2013).

Utfallsvariabler i studien inkluderar bland annat kort- och långtidsuppföljningar rörande antal sammanbrott och antal placeringar. Korttidsuppföljningarna (t. ex. efter 1 år) kommer ligga till grund för beslut i Studie 2 om instrumentval.

\section{Studie 2: Utveckling och testning av en fullständig utredningsmodell och handbok}

Studie 2 avser utveckla och testa en strukturerad helhetsmodell för familjehemsutredningar baserad bland annat på resultaten från Studie 1, men som också bygger vidare på de två redan existerande verktygen BRA-fam och Familjehemsvinjetter. Modellen innefattar även kunskap från rättspsykologisk forskning och erfarenheter från andra utredande samhällskontexter (t. ex. asylförsäkrings- och brottsutredningar). Ett preliminärt exempel på steg modellen för familjehemsutredningar skulle kunna innefatta ses nedan. Varje steg ska beskrivas utförligt i en övergripande handbok för modellen, som kommer finnas öppet tillgänglig att ladda ner från projekthemsidan.

1. Screening med BRA-fam

2. Registerutdrag

3. Hembesök med ett första samtal och uppföljning av eventuella riskfaktorer

4. Psykologiska bedömningsinstrument*

5. Familjehemsvinjetter

6. Efterforskningar* (t. ex. sociala medier och referenstagning)

7. Djupintervju: narrativ personlig intervju*

8. Övergripande bedömningsmall* (liknande den som ingår i BRA-fam)

9. Beslut: ja/nej/avvakta*

10. Återkoppling

Stjärnmärkta steg markerar de enskilda steg som avses utvecklas inom ramen för det aktuella projektet.

Utöver detta kommer handboken, liksom Gyulai et al’s (2013) handbok för migrationshandläggare, innefatta information om de potentiella tankefällor en beslutsfattare kan hamna i, så som tunnelseende, bekräftelsebias (confirmation bias), intuitivt beslutsfattande ("magkänsla”), felaktig övertygelse om att ha rätt; och hur man aktivt kan motverka risken för att falla offer för sådana tankefällor (t. ex. betydelsen av korrekt feedback på huruvida ens beslut var riktigt [Hogarth, 2001] och att tillämpa en "djävulens advokat” i arbetsgruppen).

Denna rättspsykologiskt inspirerade utredningsmodell kommer att jämföras med traditionella utredningsmodeller (utredning-as-usual) i uppföljningar, på ett antal utfallsvariabler (t. ex. antal placeringar och sammanbrott) som identifieras som viktiga i samverkan med våra samarbetspartners inom socialtjänsterna. Studie 2 förbereder även för långtidsuppföljning av bland annat antal sammanbrott i godkända familjer. 


\section{Referenslista för ansökan}

Brown, H., Sebba, J., \& Luke, N. (2015). The recruitment, assessment, support and supervision of lesbian, gay, bisexual and transgender foster carers. Rees Centre.

Button, K. S., Ioannidis, J. P., Mokrysz, C ., Nosek, B. A., Flint, J., Robinson, E. S., \& Munafò, M. R. (2013). Power failure: why small sample size undermines the reliability of neuroscience. Nature Reviews Neuroscience, 14, 365-376.

Enell, S., Hultman, M., \& Jergeby, U. (2008). Bedömningsmetoder vid rekrytering av familjehem: En systematisk kunskapsöversikt. Institutet för utveckling av metoder i socialt arbete (IMS), Socialstyrelsen.

Fonagy P., Luyten P., Moulton-Perkins A., Lee Y.-W., Warren F., Howard S., et al. (2016).

Development and Validation of a Self-Report Measure of Mentalizing: The Reflective Functioning Questionnaire. PLoS ONE 11(7): e0158678. https://doi.org/10.1371/journal.pone.0158678.

Forslund, T., Granqvist, P., van IJzendoorn, M. H., Sagi-Schwartz, A., Glaser, D., Steele, M., ... \& Duschinsky, R. (2021). Attachment goes to court: child protection and custody issues. Attachment \& Human Development, 1-52.

Gyulai, G., Kagan, M., Herlihy, J., Turner, S., Hárdi, L., \& Udvarhelyi, É. T. (2013). Credibility Assessment in Asylum Procedures - A Multidisciplinary Training Manual. Hungarian Helsinki Committee. ISBN: 978-615-5215-12-4.

Hazan, C., \& Shaver, P. (1987). Romantic love conceptualized as an attachment process. Journal of Personality and Social Psychology, 52, 511-524.

Hendrix, S. K. \& Ford, J. (2003). Hardiness of foster families and the intent to continue to foster. Journal of Family Social Work, 7, 25-34.

High-Value Detainee Interrogation Group (2016). Interrogation: A Review of the Science. Hämtad 2021-03-18 från https://www.fbi.gov/file-repository/hig-report-interrogation-a-review-of-thescience-september-2016.pdf/view/.

Hogarth, R. M. (2001). Educating intuition. Chicago: University of Chicago Press.

Inspektionen för Vård och Omsorg (IVO). (2017). Barns rätt till familjehemsvård av god kvalitet. Granskning av socialtjänstens myndighetsutövning rörande familjehemsplacerade barn. IVO 201715.

Jonsson, G., \& Kälvesten, A. L. (1964). 222 Stockholmspojkar: en socialpsykiatrisk undersökning av pojkar i skolåldern. Uppsala: Almqvist \& Wiksell. 
Kennedy, B. \& Thorpe, R. (2006). Selecting foster carers: could personnel psychology improve outcomes? Adoption \& Fostering, 30, 29-38.

Kronkvist, O. (2020). Polisförhör. Metoderna, forskningen och lagen. 2:a upplagan. Malmö: Gleerups Utbildning. ISBN: 9789140692191.

Kälvesten, A. L., \& Meldahl, G. (1982). Familjepsykologi: en handledning i intervju- och tolkningsmetodik. Stockholm: LiberFörlag. ISBN 91-40-30565-1.

La Rooy, D., Brubacher, S. P., Aromäki-Stratos, A., Cyr, M., Hershkowitz, I., Korkman, J., ... \& Stewart, H. (2015). The NICHD protocol: a review of an internationally-used evidence-based tool for training child forensic interviewers. Journal of Criminological Research, Policy and Practice, 1, 76-89.

Loftus, E. F., \& Palmer, J. C . (1974). Reconstruction of automobile destruction: An example of the interaction between language and memory. Journal of Verbal Learning and Verbal Behavior, 13, 585-589.

Luke, N., \& Sebba, J. (2013). How are foster carers selected. An international literature review of instruments used within foster carer selection. Rees Centre.

McCrae, R. R., \& Costa, P. T. (1987). Validation of the five-factor model of personality across instruments and observers. Journal of Personality \& Social Psychology, 52, 81-90.

McNally, R. J. (2005). Remembering trauma. Harvard University Press; London, England.

Means, B., Nigam, A., Zarrow, M., Loftus, E. F. \& Donaldson, M. S. (1989). Autobiographical memory for health-related events. National Center for Health Statistics. Vital and Health Statistics, 6, 1-37.

Memon, A., Meissner, C . A., \& Fraser, J. (2010). The Cognitive Interview: A meta-analytic review and study space analysis of the past 25 years. Psychology, Public Policy, and Law, 16, 340-372.

Moritz, A. R. (1981). Classical mistakes in forensic pathology. Am J Forensic Med Pathol, 2, 299 308.

Orbach, Y., Lamb, M. E., Sternberg, K. J., Williams, J. M. G., \& Dawud-Noursi, S. (2001). The effect of being a victim or witness of family violence on the retrieval of autobiographical memories. Child Abuse \& Neglect, 25, 1427-1437.

Rasmusson, B., \& Regnér, M. (2013). Ett utvalt hem till ett utvalt barn. Familjehemsutredningar och socialt arbete i praktiken. Stockholm: Natur och Kultur.

Roberts, K. P., \& Powell, M. B. (2001). Describing individual incidents of sexual abuse: a review of research on the effects of multiple sources of information on children's reports. Child Abuse \& Neglect, 25, 1643-1659. 
Scoboria, A., Memon, A., Trang, H., \& Frey, M. (2013). Improving responding to questioning using a brief retrieval training. Journal of Applied Research in Memory and Cognition, 2, 210-215.

Socialstyrelsen. (2014). Manual till BRA-fam. En standardiserad bedömningsmetod för rekrytering av familjehem. Stockholm: Socialstyrelsen. ISBN 978-91-7555-154-8.

Socialstyrelsen. (2020). Manual till Familjehemsvinjetter. En standardiserad bedömningsmetod för utredning av familjehem. Artikelnummer: 2020-5-6703. Stockholm: Socialstyrelsen.

Socialstyrelsen. (2020a). Statistik om socialtjänstinsatser till barn och unga 2019. Stockholm: Socialstyrelsen.

Socialstyrelsen. (2021). Insatser för att motverka fortsatt normbrytande beteende och återfall i brott - Kunskapsstöd med rekommendationer för socialtjänstens arbete med barn 6-17 år. Stockholm: Socialstyrelsen. ISBN 978-91-7555-573-7.

Statens beredning för medicinsk och social utvärdering (SBU). (2017). Insatser för bättre psykisk och fysisk hälsa hos familjehemsplacerade barn. Stockholm: Statens beredning för medicinsk och social utvärdering. ISBN 978-91-88437-07-5.

Statens beredning för medicinsk och social utvärdering (SBU). (2018). Behandlingsfamiljer för ungdomar med allvarliga beteendeproblem - Treatment Foster Care Oregon. En systematisk översikt och utvärdering inklusive ekonomiska och etiska aspekter. Rapport nr 279. Stockholm: Statens beredning för medicinsk och social utvärdering. ISBN 978-91-88437-21-1.

UNHCR. (2013). Beyond proof: Credibility assessment in EU asylum systems. Brussels: United Nations High Commissioner for Refugees.

Sacker, A., Lacey, R., Maughan, B., \& Murray, E. T. (2021, February 3). Out-of-home care in childhood and socio-economic functioning in adulthood: ONS Longitudinal Study 1971-2011. Preprint: https://doi.org/10.31235/osf.io/f6b5x/.

Suengas, A. G., \& Johnson, M. K. (1988). Qualitative effects of rehearsal on memories for perceived and imagined complex events. Journal of Experimental Psychology: General, 117, 377389.

Thiblin, I., \& Michard, J. F. (2015). Rättsmedicin i teori och praktik: En guide för läkare och jurister. 2:a upplagan. Lund: Studentlitteratur.

Vinnerljung, B., \& Sallnäs, M. (2008). Into adulthood: a follow-up study of 718 young people who were placed in out-of-home care during their teens. Child \& Family Social Work, 13, 144-155.

Willén, R. M., Granhag, P. A., \& Strömwall, L. A. (2016). Factors Affecting Two Types of Memory Specificity: Particularization of Episodes and Details. PLoS ONE, 11, e0166469. DOI:

10.1371/journal.pone.0166469. 
Willén, R. M., \& Kronkvist, O. (2021). The New Kälvesten Method: Swedish Assessment of Foster Parent Suitability Gives Cause for Concern. Manuscript under preparation. 